\title{
Integrating sustainable development and brownfields reuse - principles and practice
}

\author{
C. N. Brooks \\ President, Greenfield Environmental Trust Group, Inc. (GETG), \\ Watertown, Massachusetts, USA \\ President, Resources for Responsible Site Management, Inc. (RRSM), \\ Watertown, Massachusetts, USA
}

\begin{abstract}
Sustainable development practices began making their debut in the US at about the same time that brownfields reuse came of age, although both have traveled independent, disconnected paths. Indisputably, reusing brownfields advances the three inter-connected pillars of sustainable development: environment (by remediating threats to public health and the environment), economy (by creating jobs or revitalizing decayed, abandoned areas), and society (by enhancing community pride and security). Furthermore, most agree that recycling landthe fundamental premise of brownfields reuse-does, in fact, represent sustainable development. However, at present there are few meaningful resources or guidelines for the holistic integration of brownfields reuse and sustainable development. Notwithstanding the separation in the policy and practice of brownfields reuse and sustainable development, both areas share many overlapping, similar and recurring issues, strategies and key success factors. The purpose of this paper is to provide an overview of the best practices in brownfields reuse and sustainable development in order to demonstrate the multiple areas of commonality and overlap in both fields. Utilizing the separate lessons learned from brownfields reuse and sustainable development, this paper offers a set of practical, guiding principles and criteria that integrate the best practices of both fields. Ultimately, this paper seeks to place brownfields reuse and sustainable development on a unified, shared path so that brownfields can be redeveloped in a truly sustainable manner.
\end{abstract}

Keywords: brownfields, redevelopment, sustainable development, best practices, smart growth, LID, green building-development. 


\section{Introduction}

In the last decade, escalating demand to redevelop contaminated sites has been driven by diverse stakeholder agendas - new jobs, tax revenues, the protection of public health, environmental restoration, a paucity of well-situated sites in high growth markets, efforts to curb sprawl, and pressure to revitalize decayed, urban centers. Today these multi-stakeholder interests continue to dominate the drive to remediate and reuse brownfields, which are estimated to number between 500,000 and 1,000,000 in the United States alone, according to a 2004 report to the US Congress. In fact, the forces pushing brownfields into the limelight have spawned a host of economic and environmental policy programs and created a US market valued at \$2 trillion in 2006. More recently, newly emerging values, priorities, markets and technologies have placed brownfields squarely at the center of broader efforts aimed at social, environmental and economic sustainability. The impetus to redevelop brownfields has assumed new urgency as communities, businesses and government grapple with rising energy costs, quality of life issues, societal and market demands for environmentally sustainable developments, and increasingly, global climate change. Brownfields reuse can and should be integrated into sustainable development initiatives, such as smart growth, low impact development (LID), transit-oriented, mixed use villages, infill redevelopment, renewable resource projects and the protection of ecological and rural lands.

That land itself is a renewable resource lies at the heart of brownfields reuse. That brownfields can and should be re-cycled in a holistic, sustainable fashionsatisfying the inter-connected needs of society, environmental and economic capacity - is the fundamental premise of this paper. Typically brownfields reuse is bifurcated, segregated or regulated separately from the techniques and practices of sustainable development. And too often sustainable, "green" developments are built on virgin, "greenfield" land, demanding new supporting infrastructure (even if less than conventional development) with its accompanying destruction of natural resources that might otherwise be preserved.

In the US, a raft of policy initiatives and government regulations either enable or encumber brownfields reuse, while sustainable development practices are either ignored, envisioned but rarely enacted, or pursued by only a handful of public and private interests. As redeveloping brownfields enters mainstream practice, and absent regulatory reform or meaningful institutionalization of a coherent process, it is incumbent on all stakeholders to ensure a sustainable approach to brownfields reuse. This paper presents a set of practical guidelines for the holistic integration of brownfields reuse and sustainable development. Based on prevailing principles, methodologies and key success factors governing both sustainable development and brownfields reuse, it identifies the areas of natural and logical overlap and commonality in the best practices for both fields. Finally, it recommends a set of multi-stakeholder principles for the sustainable redevelopment of brownfields. 


\section{Brownfields- the challenge and the opportunity}

For more than a decade, brownfields have been blamed for countless multistakeholder issues: lost value, jobs and tax revenues; unmitigated threats to public health and the environment; and seemingly unlimited financial and societal liability. The four most significant barriers to reuse are: unknown, potentially unlimited liability for expensive clean-ups and lawsuits under US hazardous waste site clean-up laws; time-consuming and expensive remediation requirements under environmental regulations; market perceptions and "stigma" that de-value such sites and raise doubts about whether they can be safely reused; and the complex transactional and development challenges to reusing such properties (as compared to virgin "greenfield" sites). Since the mid-1990's, when the ubiquitous nature of these sites was first recognized, a host of government initiatives, technologies and innovative financing and development tools have been created to address these barriers to reuse.

\subsection{Unknown, unlimited liability}

Unknown, unlimited liability has been a threshold issue since 1980 when the US Congress enacted the superfund (superfund refers to the Comprehensive Environmental Response, Compensation and Liability Act (CERCLA)) laws mandating clean-up of the country's most hazardous waste sites under a "polluter pays" principle. Under superfund's 'strict, joint and several' liability scheme, current and past owners, tenants, contractors, transporters and others are named Responsible Parties (RPs) and can be compelled by the US Environmental Protection Agency (EPA) (or its state government counterpart) to pay for and clean-up these sites regardless of how much it costs, how long it takes, or whether they actually contributed to contamination. This onerous liability scheme has had a chilling effect on US real estate: buyers shunned sites with real or perceived potential contamination to avoid RP status; owners chose to 'moth-ball' rather than sell properties for which they had no continuing use to avoid triggering potentially very expensive clean-up obligations if hazards were discovered; and communities were left with idle, polluted sites and their accompanying lost jobs, taxes, health threats and decay. Although many brownfields are not heavily contaminated, the risk of being named an RP made buying, selling or leasing these sites untenable. Sadly, liability concerns extended to very costly "third party" lawsuits where an RP could be sued for human health impacts attributed to contamination at a site (so called "toxic tort" claims) or lost property values due to the migration of contaminants onto nearby land. The result was property gridlock.

State governments responded to this gridlock by adopting "voluntary clean-up programs" (VCPs) whereby buyers and owners could choose to clean-up sites under defined clean-up standards. In exchange, environmental regulators granted assurance and closure that the VCP parties had resolved their liabilities at a site. To date all fifty states have adopted some form of a VCP although programs vary widely from state to state. For its part, in the mid-1990s the 
federal government, through EPA, launched several programs to address liability, including issuance of Covenants Not To Sue (CNTS) Agreements, later termed Prospective Purchaser Agreements (PPAs), to buyers who had not contributed to site contamination (i.e., "innocent landowners") and were willing to perform certain tasks (related to site remediation) in exchange for a CNTS or PPA. More significantly, after years of wrangling, in 2001 the US Congress passed the Small Business Liability Relief and Brownfields Revitalization Act (SBLR-BRA) which codified a process that relieved innocent landowners of liability under superfund, so long as they complied with specific requirements for property due diligence, known as All Appropriate Inquiry (AAI). During this timeframe, private insurers began developing new insurance products designed to protect purchasers from clean-up cost overruns, future regulator enforcement action and even third party (including toxic tort) claims.

Neither state VCPs nor federal reforms have been a panacea for US brownfields, in part, because they exclude heavily contaminated sites, third party claims, and, with few exceptions, parties that may have contributed to contamination. Also, there are still scenarios under which an entity could be named an RP and thus held liable for exorbitant clean-up costs, especially large corporations (the so-called "deep pockets" often targeted by government regulators) who still lack incentive to reuse idled sites and thus keep them mothballed. Private insurance also has limitations, including costly premiums and limited 'terms' of coverage. The keys to successfully leveraging these liability protection mechanisms include: "micro-managing" the details before and during the transactional and implementation phases; utilizing the necessary technical and legal experts very early in the process; and partnering with government regulators to achieve a timely outcome.

\subsection{Time-consuming, expensive clean-ups}

Time-consuming, expensive clean-up requirements, with or without regulator enforcement, contribute to the gridlock keeping US brownfields idle and abandoned. To begin addressing these issues, many state VCPs feature complementary brownfield programs that provide financial, technical and other resources to help reduce the cost and complexity of reusing contaminated land. Financing programs include grants, low-interest loans and tax incentives (abatements, credits, refunds and tax increment financing). VCPs often include established schedules for regulatory approvals that better conform to development needs.

Numerous federal programs have been launched to help address the costs of assessment and clean-up of brownfields. Beginning in the mid-1990s, EPA began offering financial assistance to communities and non-governmental organizations (NGOs) seeking to revitalize brownfields. Passage of the SBLRBRA increased EPA funding for these programs by up to $\$ 200$ million per year, covering grants, revolving loans, direct clean-up costs and job training-most of which benefit communities or states seeking to remediate and redevelop brownfield sites. Similarly other federal agencies-US Department of Commerce (DOC), US Department of Housing and Urban Development (HUD), 
US Department of Transportation (DOT), Department of Agriculture (DOA), and US Army Corps of Engineers (ACE) - have launched brownfields initiatives aimed at job creation, housing, transportation and infrastructure revitalization and the restoration of rural lands. All programs are designed to infuse critical "public capital" into brownfields to incentivize other stakeholders to participate in redevelopment (i.e., closing the financing gap between brownfield and greenfield sites).

Based on experience, key success factors in utilizing these programs include: (i) structuring multi-stakeholder public-private partnerships that leverage public capital to create value and save costs as an inducement for more risk-averse private investment; (ii) recognizing that those attributes which made a site attractive for use in the first place (infrastructure, access to labor and markets, etc.) often have not changed and leveraging such attributes as part of a site's reuse can save redevelopment costs and enhance eligibility for public funds; (iii) understanding that a community-based approach is critical, not only because land use is governed locally in the US, but also because communities are often the most eligible and preferred recipients of public capital that benefits the panoply of other stakeholders.

One of the most popular reforms for addressing clean-up cost and efficiency is Risk Based Corrective Action (RBCA) - a risk-based approach to managing site contamination. Under RBCA, the level of clean-up is governed by the future use of the property because the nature of such reuse drives the risk to human health and the environment. RBCA entails a scientific assessment of risk posed by specific, on-site contaminants and the likelihood and mechanism by which humans and the environment might be harmed by such contaminants now and in the future (a "risk assessment"). Clean-up goals are based on reducing risk to a level whereby contaminants no longer threaten public health and the environment. For example, a site reused for a playground requires a more stringent clean-up than one redeveloped for light industry. RBCA is often used when technological, practical or economic constraints preclude elimination of contaminants, which are then left on-site. At these sites, the risk-based approach may include an "engineered control" (such as a cap or a fence) to prevent contact with contaminants and an "institutional control" (such as a deed restriction, covenant, or zoning overlay) to provide the legal or administrative mechanism to ensure that the engineered control remains in place and is maintained in perpetuity. Proponents of RBCA argue that it promotes: more efficient cleanups-focusing on the highest risk issues and avoiding unnecessary mitigation of low risks; greater flexibility in site remediation; consistency in clean-up levels across jurisdictions; and remediation and reuse of sites that might otherwise be ignored by limiting clean-up to the levels required for current and future use of the property. Opponents bemoan the contamination left in-place at many RBCA sites and the lack of reliable mechanisms to ensure that future site users will comply with "institutional controls".

Beyond RBCA, new technologies have also been developed to more effectively, efficiently remediate contamination such as: phytoremediation (remediating with plant systems); bioremediation (remediating with 
microorganisms or fungi); thermal treatments (using very high temperatures to destroy or facilitate extraction of contaminants); and soil vapor extraction.

Keys to success with RBCA or new remediation technologies include: (i) early identification of and community buy-in to the specific planned reuse in order to focus the risk-assessment on realistic anticipated risk (versus all potential risks for all types of uses - from residential to industrial); (ii) securing early end-user commitments to a site so they can participate in risk management and remediation decisions; (iii) integrating risk management tools and remedial action into the planned reuse for a property (e.g., siting and building parking facilities or building foundations to function as caps on contaminated soil); (iv) analyzing full lifecycle economics that fairly and accurately compare the costs of remediation to the total costs (to all stakeholders) of maintaining, monitoring and enforcing institutional controls; and (v) ensuring long-term preservation of the remedy through proactive community participation in designing clear, unambiguous, enforceable institutional controls because the community will be living with a site long after the other stakeholders have moved on.

\subsection{Stigma}

Stigma refers to market devaluation and fear of real or perceived contamination at brownfield sites and represents one of the most challenging barriers to site reuse. Stigma operates like a self-fulfilling prophesy in that fear of site's low value and unsafe conditions prevents remediation and reuse, furthering site stigma because unaddressed contamination can and does migrate to surrounding areas just as the decay of a stigmatized site spreads to nearby properties and neighborhoods. Stigma can endure long after a site has been remediated, especially if it posed a real or perceived threat to public health. Sites that have been the subject of extensive litigation, especially around human health issues (i.e., toxic tort), can be difficult to redevelop because the publicity and notoriety of lawsuits creates further stigma and doubt about whether they can indeed be safely reused. Nevertheless, redeveloping highly stigmatized sites can have farreaching, multi-stakeholder benefits ranging from catalyzing areawide revitalization to creating new real estate value. Based on experience, stigma can be overcome through: multi-stakeholder collaboration on remediation and redevelopment, including goals, expectations and results; meaningful, inclusive stakeholder communications, outreach and education; and public-private partnerships to secure public investment in a stigmatized site that can help convince private investors that a site is safe to reuse and thus catalyze reuse.

\subsection{Complex transactional and vertical development issues}

Brownfields pose much more complex transactional and vertical development challenges than conventional real estate development. Nevertheless, these sites can be developed for the benefit of public and private interests by utilizing the tools, strategies and techniques outlined above. Several factors critical to successfully navigating these challenges include: vigilant, very detailed management of all phases of the transaction and development; and retention of 
the necessary technical, legal, financial and communications experts to address these issues in an integrated, multi-disciplinary fashion at the onset of a project.

\section{The practice of sustainable development}

As an idea, a goal and a mandate, sustainable development means many things to many people. The most common definition- "development that meets the needs of the present without compromising the ability of future generations to meet their own needs," [1] - fuses "environment" and "development". Many have capitalized on the ambiguity in this definition introducing broader or more constrained interpretations of what constitutes "environment" and "development"; thus, concepts like biodiversity, ecosystem renewal, conservation, poverty, justice, equity, and freedom have been added to the meaning of sustainable development. Notwithstanding different terminology and language, most agree that there are three fundamental pillars of sustainable development-economy, environment, and society. Many also can and do accept that sustainable development represents a "condition" or "state of being" (as compared to an outcome) whereby the oft-competing goals and needs of these three global spheres operate in harmony and equilibrium. Practitioners face the unresolved challenge of translating such esoteric concepts into useful, practical paradigms that answer the economic, environmental and societal goals and realities of their specific community in ways that honor their community's inter-dependence and inter-connection to all other communities. In the US, many programs and practices have been adopted in the last two decades to promote the principles of sustainable development. Some of the most evolved, widely known initiatives, their barriers to implementation and key success factors are described hereafter.

\subsection{Smart Growth}

Smart Growth might be termed a "movement" aimed at curbing suburban and exurban sprawl. It originates at a grass roots level and is legitimized by governmental and institutional programs. Smart Growth seeks to manage growth and its impacts on a particular community in a sustainable fashion. Its focus is on the revitalization of declining urban centers through creation of towncentered, transit- and pedestrian-oriented, mixed use developments with diverse residential, commercial and industrial uses and protected open space and ecological resources. The guiding principles of Smart Growth promote healthy, vibrant, diverse communities that include: mixed land uses; compact buildings; diverse housing options; walkable neighborhoods; distinctive, attractive communities with a strong sense of place; preserved open space, farmland and sensitive environmental areas; strengthened existing communities; transportation choices; predictable, fair, cost effective development decisions; and community and stakeholder collaboration [2]. Smart Growth plans are implemented, in part, by: new or revised local building codes; regulations and zoning laws to promote and incentivize high-density, mixed-used, transit-oriented developments; new approaches and technologies for walkable, compact town-centers and protected 
natural environments; and public-private partnerships. Smart Growth can be hampered by traditional zoning and local land use laws, which often segregate land uses (separating residential from commercial areas) and create large lots inconsistent with compact, walkable villages or a diverse housing stock. Conflicting, uncoordinated political jurisdictions also impede Smart Growth.

\subsection{Green Building and Development}

Used here, Green Building and Development (GB\&D) refers to the technologies, practices and tools intended to reduce the impact of the built environment on the natural environment (in contrast to "conventional" building and development which is usually a source of new waste and adverse environmental impacts).

\subsubsection{Overall goals of GB\&D}

GB\&D is manifested by: principles that recognize the inherent connectivity between a building, its occupants and its environment; and practices set forth in five basic GB\&D goals (discussed below): (i) to utilize efficient, renewable energy; (ii) to minimize environmental impacts; (iii) to conserve natural resources; (iv) to enhance indoor air quality; and (v) to engage the community.

3.2.1.1 Efficient/renewable energy resources This is a GB\&D goal that seeks to minimize non-renewable and maximize renewable energy resources in the construction and operation of a building or development by: utilizing active, renewable energy technologies (wind, hydro, biomass and geothermal power); integrating passive resources (solar power, natural lighting and natural shading); leveraging prevailing climate and environmental conditions in design and operations; using energy-efficient equipment, appliances and fenestrations; and optimizing the siting, orientation and "envelope" of a building. Some of the government- and NGO-created programs that promote efficient, renewable energy resources in the US include: EPA and US Department of Energy (DOE) ENERGY STAR program which qualifies certain products, appliances and technologies as energy efficient; Sustainable Buildings Industry Council, an NGO dedicated to energy efficient buildings; and DOE's Million Solar Roofs Initiative. Successful application of efficient, renewable energy requires: (i) an integrated, iterative, multi-disciplinary design process; (ii) assembling a team with the requisite expertise committed to realizing a project's energy goals; (iii) analyzing full lifecycle costs (to balance and offset front-end costs with longterm savings); and (iv) multi-stakeholder commitment to and recognition of the value (economic, market, and goodwill) of alternative, renewable energy. Major barriers include: (i) higher initial investment; (ii) lack of organizational and cultural commitment to sustainable energy and awareness of options; (iii) some location and landscape impacts from siting certain facilities (e.g., solar panels, wind turbines) and the resultant NIMBY (Not In My Back Yard) response from host communities; and (iv) industry reluctance to use full-lifecycle costs (compared to traditional pro forma analyses) (NIMBY is the acronym for Not In My Back Yard. The NIMBY Principle refers to a community's response when it opposes the siting of unwanted facilities in their neighborhood, which are objectionable to the residents (such as an incinerator, an airport, a waste disposal 
facility, a power plant and/or a prison) but may provide needed public or commercial services).

3.2.1.2 Minimizing environmental impacts This is a GB\&D objective that strives to minimize disturbance and preserve integrity of the natural environment through a holistic approach that integrates the built environment into its natural surroundings. One of the most widely practiced methods for minimizing environmental impacts is Low Impact Development (LID) - a technology-driven system that emphasizes the value of water resources by focusing on site hydrogeology and the costs of stormwater management. LID uses innovative techniques to store, filter, evaporate and detain run-off by "imitating" a site's natural (pre-development) conditions in order to minimize development stormwater run-off and preserve existing groundwater recharge patterns. LID maintains pre-development flow patterns by minimizing how new impervious surfaces can adversely impact the amount, frequency, and quality of stormwater runoff through small landscape features on individual lots (such as on-lot microstorage, functional landscaping and grading, open drainage swales, disconnected flowpaths, and bio-retention and filtration areas [3]).

Another technique for minimizing environmental impacts is "natural" or "green" landscaping, which includes planting native species, drought-tolerant plants in arid regions, wind-tolerant plants in high wind areas of a development, and naturally occurring wetland plants in waterways and detention areas. (Examples of green landscaping include planting deciduous trees for summer shade and winter sun or evergreens for windbreaks in north-facing locations - to ensure solar benefits of south-facing areas (Smart Communities Network, www.smartcommunities.ncat.org).)

Some of the keys success factors for LID and/or green landscaping include: (i) an integrated, iterative, multi-functional site design process; (ii) a multidisciplinary team approach; (iii) multi-stakeholder recognition of water as a resource and full lifecycle costs of stormwater (mis)management borne by direct stakeholders and society; and (iv) effective land use covenants to ensure proper system maintenance in perpetuity. The major barriers are: (i) a dearth of appreciation, recognition or valuation of water as a resource and the total price of stormwater management; (ii) an absence of knowledge or awareness of LID and green landscape techniques and technologies; and (iii) the lack of regulatory or legal incentives.

3.2.1.3 Conserving natural resources This is a fundamental goal of GB\&D. It extends across the lifespan of a project (including construction and operations) and encompasses programs such as recycling, waste minimization, material reuse and water conservation. Green roofs (i.e., roofs with plant cover) help conserve natural resources (by lowering cooling costs and preventing heat islands) and minimize environmental impacts (by preventing stormwater runoff, increasing air quality and available habitat). Conservation initiatives represent one of the most cost effective strategies for minimizing operating costs and environmental damage from development. The success of such programs depends on early integration of conservation measures into design and widespread organizational 
buy-in to and adoption of conservation values. Conservation efforts are often hampered by: prevailing practices and inertia; a lack of financial and regulatory incentives; and misunderstanding as to the true benefits of natural resource conservation.

3.2.1.4 Enhanced indoor air quality This is a goal that is increasingly linked to the health and productivity of building occupants. Because energy-efficient buildings are airtight, they increase the risk of indoor air pollution. Practices adopted to maximize indoor quality, include: using materials and products with low chemical content; and mechanical systems to provide fresh air into buildings and indoor air exchange. The success of indoor air quality programs depends on: (i) early integration of products and systems into development design; (ii) explicit analysis of employee health and productivity gains (fewer sick days, greater productivity, etc.; and (iii) recognition of reduced liability benefits by avoiding "sick building" issues.

3.2.1.5 Community engagement This is a GB\&D goal that seeks to integrate sustainable development into the surrounding environment by preserving and protecting community assets - cultural, historical and aesthetic - and incorporating beneficial public amenities (transportation services, pedestrian and bicycle paths, parks and open space). Successful community engagement requires: proactive, inclusive approaches to community participation; clear, early understanding of community goals, needs and expectations; and effective, honest multi-stakeholder dialogue as to how such goals and needs can (or cannot) be met. Barriers include: fear of community participation (and its perceived loss of control); and a lack of appreciation for the broad value of community participation (approvals, incentives and consent).

\subsubsection{GB\&D for practitioners}

The above five GB\&D objectives are embedded in broader strategies and programs aimed at promoting sustainable development pursued by various government agencies, NGOs and, to a lesser degree, private interests. Most US GB\&D programs are voluntary initiatives designed to incentivize and promote sustainable development, although recently governmental entities have begun mandating GB\&D practices in projects that utilize taxpayer funds.

One of the most widely recognized systems and standards for the voluntary pursuit of sustainable development is Leadership in Energy and Environmental Design (LEED) certification, which is administered by the non-profit US Green Building Counsel (USGBC). LEED certification measures the sustainability of a building in a four-level system (Certified, Silver, Gold and Platinum) depending on how many credits are earned in five LEED categories (sustainable sites; water efficiency; energy and atmosphere; materials and resources; and indoor environmental quality). LEED covers new commercial construction, renovation, interiors and building operations. Standards for commercial "core and shell" and new home construction, as well as neighborhood developments are planned.

Overall, successful GB\&D practices require: (i) early marshalling of multidisciplinary resources and expertise to optimize GB\&D in an iterative process; 
(ii) proactive, inclusive multi-stakeholder dialogue and community partnering; (iii) full lifecycle cost-to-benefit analyses (that ideally include costs to society and the environment); and (iv) organizational culture, priorities and leadership that recognizes the value of "going green" externally (by markets, shareholders and customers) and internally (by employees and host community). Barriers to GB\&D include: (i) lack of knowledge and awareness of sustainable strategies; (ii) higher front-end costs; (iii) prevailing industry practices (inertia); (iv) a paucity of data documenting economic benefits (such as reduced operating costs or greater employee productivity); and (v) lack of meaningful regulatory incentives (or penalties) and reliance on voluntary participation.

\section{Criteria and guidelines for sustainable brownfields reuse}

Despite numerous recurring themes and patterns, brownfields reuse and sustainable development in the US are often pursued along separate, unrelated paths. Yet the processes, strategies and issues attendant to brownfields reuse should resonate with the sustainable development community and vice versa. Indeed the interests of efficiency alone should compel practitioners to consider the shared, overlapping and familiar best practices of both pursuits, despite their fragmented, piecemeal and diverse programs and laws. In fact, the larger quest for global harmony in economy, environment and society mandates explicit fusion of brownfields reuse and sustainable development into an integrated, holistic, mutually beneficial process.

Based on experience, the keys to success for both sustainable development and brownfields reuse include community-engagement and leadership, multistakeholder collaboration, public-private partnerships, and multi-disciplinary teams in a front-end loaded, bottom-up, detail-oriented, iterative, incremental process. Specifically, practitioners can begin merging brownfields reuse and sustainable development into a cohesive, integrated process by evaluating, adopting and incorporating the following critical success factors and strategies (not presented in recommended sequence or order of importance):

(1) Early mobilization of critical expertise and resources;

(2) Multi-disciplinary team approach to analysis and decision-making;

(3) Iterative, incremental process (detail orientation and value engineering);

(4) Multi-stakeholder alignments (more inclusive participation);

(5) Public-private partnerships (to leverage public resources for private participation and investment);

(6) Community alliance, collaboration and leadership;

(7) "Begin with the end" (end-use/-user and end goals for environment, economy and society);

(8) Integration of the natural, remediated and built environments;

(9) Full lifecycle economics (assessing long-term costs/benefits and the value of non-economic benefits); and

(10) "Smart Re-Growth" (leveraging location and original site assets for the future)

The above list does not constitute a comprehensive guide for integrating brownfields reuse and sustainable development. It is intended to provide a set of 
governing principles, best practices and practical strategies to help advance the long-term fusion of brownfields reuse and sustainable development. The issues, challenges, needs and goals are always specific to a particular site, community and the key stakeholders; thus the role, importance and process for application of these strategies must recognize the unique circumstance of each site.

\section{Conclusions}

Brownfields reuse clearly promotes harmony among the three inter-connected pillars of sustainable development: environment (by remediating threats to public health and the environment), economy (by creating jobs and revitalizing decayed, abandoned areas), and society (by enhancing community pride and security). Experience with the practice of brownfields reuse and sustainable development demonstrates broad commonality in their respective issues and challenges. Yet there are few meaningful resources or guidelines for the holistic integration of brownfields reuse and sustainable development. Faced with a continued absence of policy initiatives, reform programs or new laws that fuse the overlapping needs and goals of sustainable development and brownfields reuse, practitioners can and should begin making brownfields reuse more sustainable by the lessons learned from each field. The best practices outlined here represent a point of entry - a place for practitioners to begin merging brownfields reuse and sustainable development into a shared, cohesive set of principles and best practices - for the mutual benefit of both endeavors. Over the long-term, comprehensive policies, guidelines, programs and regulations will be required to render brownfields redevelopment truly sustainable. Only with such long-term solutions will there be significant, meaningful progress toward the global mandate for true harmony amongst the competing needs of a stable economy, a healthy environment, long-term quality of life and genuine social progress for all communities and stakeholders.

\section{Acknowledgement}

Resources for Responsible Site Management, Inc. is the named US Federal District Court Trustee for the Industri-plex Superfund Site Custodial Trust.

\section{References}

[1] United Nations World Commission on Environmental and Development, WCED, Our Common Future, Oxford University Press, 1987, p. 40. (1987 UN Brundtland Commission)

[2] Smart Growth Principles, United States Office of the EPA 231-F-01-001A, Environmental Protection Administrator April 2001, 1EPA Agency (MC 1808), www.epa.gov.

[3] Low-Impact Development Design Strategies: An Integrated Design Approach, Prince George's County, Maryland, Department of Environmental Resources, Programs and Planning Division, June 1999. 